\title{
The effects of peripheral and central fixation on a Poggendorff-like vernier alignment task
}

\author{
PETER WENDEROTH, DENNIS WHITE, and HELEN BEH \\ University of Sydney, Sydney, Australia 2006
}

\begin{abstract}
Observers judged oblique line-to-dot alignments both when the oblique line abutted a vertical inducing line (Condition $\mathrm{E}$ ) and in the absence of the vertical line (Condition $\mathrm{C}$ ). Five groups of 10 subjects each completed these $C$ and $E$ judgments under one condition of inspection. There were three major findings: (1) contrary to expectations arising from results obtained by Novak (1966), there was no difference between the condition in which observers were instructed to fixate the point at which the oblique line abutted the inducing line and the condition in which free inspection was permitted; (2) contrary to a recent report by Greist and Grier (1977), alignment errors were not eliminated in conditions involving fixation directly above or below the point of abuttal; instead, effects similar to those reported by Prytulak (1973) occurred in both Conditions $C$ and $E$, and these effects consequently were not significant in the corrected (E-C) difference measures; and (3) when alignment errors were converted to angular displacements, mean errors decreased linearly as a function of the distance between the tip of the oblique line and the response dot. This third finding was attributable to nonzero intercepts of error functions, and the result was considered in relation to the tenability of various hypotheses concerning the nature of abutting line effects.
\end{abstract}

In a recent investigation of the Poggendorff illusion Greist and Grier (1977) reported that peripheral fixation to the left or right of the stimulus had no effect on the magnitude of the illusion but that peripheral vertical fixation abolished the illusion entirely, whether the fixation point was $3.12^{\circ}$ above or below the stimulus, the total size of which was about $1.25^{\circ}$. Earlier, Novak (1966) had found a significant reduction in the Poggendorff effect with central fixation, compared to the illusion which occurred under completely free inspection. Novak's stimulus was relatively large, of the order of $13^{\circ}$ in height.

Neither of these studies used a control condition in which the subject aligned a line to the transverse segment in the absence of the inducing parallels. The use of such a control is advisable for at least two reasons. First, smaller but significant alignment errors, in the same direction as the Poggendorff effect, occur with such a parallelless Poggendorff figure (Curthoys, Wenderoth, \& Harris, 1975; Day, 1973; Day \& Dickinson, 1976; Wundt, 1886), and it is of interest to establish whether instructed fixation affects only this vernier alignment

This research is part of a project (Grant No. A74/15177) supported by the Australian Research Grants Committee in 1975 and 1977. Peripherals and software for the display were developed by Mike Cooper, Alan Parkinson, and John Holden, to whom we are grateful; Phil Greenwood and Margie Morgan assisted in collecting the data. We particularly thank Alan Parkinson for helpful discussion of a first version of this paper and an unknown referee who provided the adequate "helicopter view" of the data. component of the full Poggendorff effect, or only the component due to the inducing effect of the parallels, or both.

Second, and perhaps more important, Helmholtz (1920) noted that a rectilinear stimulus appears concave towards an eccentric fixation point, such that the extremities of the stimulus appear displaced towards the fixation point. Prytulak (1973a, 1973b) systematically investigated this effect using a vernier alignment ("parallelless Poggendorff") stimulus composed of a $1^{\circ} 16^{\prime}$ oblique line segment and an alignment dot $3^{\circ} 11^{\prime}$ from the near tip of the line. He found that the effect occurred with fixation points lying off the oblique stimulus line's axis (eccentric fixation) and within the vicinity of the stimulus line; but with fixation more distal in the region of the response dot, the opposite effect occurred. The former result, with fixations $10^{\circ}$ left or right of vertical stimuli was also obtained by Parlee (1972). ${ }^{1}$

Prytulak's and Parlee's results suggested the following predictions. Fixation directly above the abutting tip of the oblique line in a Poggendorff figure in which the transverse segment is oriented $45^{\circ}$ (top to the right) and in which the segment to be aligned (e.g., a dot) is above and to the right of the line segment, should result in the dot's appearing too high, concave towards the fixation point. Since this is also the direction of the usual Poggendorff illusion, with or without inducing parallels, fixation above the line tip of such a figure should enhance the Poggendorff effect. On the other hand, fixation below the figure should 
result in the dot's appearing too low, an effect directionally opposite to the usual Poggendorff effect. Thus, fixation below the stimulus should detract from the illusion. Clearly, these predictions are not in accord with the results obtained by Greist and Grier (1977), who found that the full Poggendorff illusion disappeared entirely whether fixation was $3.12^{\circ}$ above or below the stimulus.

The purpose of the experiment reported here, then, was to measure dot-to-line alignments under various conditions of fixation using a $45^{\circ}$ oblique transverse segment, in both the presence and absence of a single, vertical inducing line which abutted the transverse segment. On the basis of the above analysis of the experiments of Prytulak and Parlee, various predictions could be made and these are discussed in detail below.

An essential question was whether fixation effects, if any, would still be evident when illusions, measured in the presence of the inducing line, were corrected for those fixation effects occurring in its absence. That is, do fixation effects occur equally with any alignment task so that they affect the parallelless and full Poggendorff illusion equally and hence do not alter the incremental effect of the inducing parallels?

A second question which the experiment was designed to answer was whether instructed fixation on the transverse line segment's tip nearest the dot would reduce the illusions which occur with or without an inducing parallel. According to Prytulak's (1973a) data, minimal or no errors occur in the absence of the inducing line with fixation anywhere along the oblique axis defined by the stimulus line. Yet Novak (1966) obtained a significant reduction in the full Poggendorff effect (i.e., with inducing parallels and two transverse line segments rather than a line and a dot) when fixation was centered between the two inducing parallels and aligned with the transverse segments. It is conceivable, of course, that such zero eccentricity fixation (in Prytulak's terms) affects the full Poggendorff efect but not the parallelless version. Since most subjects in our previous experiment (e.g., Wenderoth, Beh, \& White, 1978), under free inspection conditions, reported that they looked mainly along the oblique line and at its tip nearest the dot, we expected no difference between a freeinspection condition and fixation of the near tip. In the present experiment, we included two line-tip fixation conditions, one at each tip of the oblique line. Figure 1 shows the four fixation points used in this experiment (A, B, U, and $L$ ) and the stimulus dimensions.

Other aspects of Figure 1, such as the response dots 1 to 10 , are explained in the Method section,

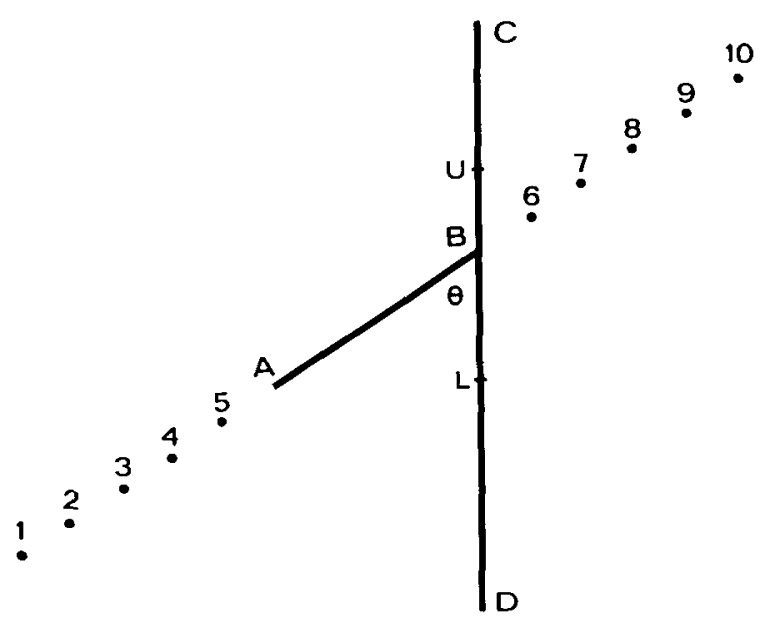

Figure 1. Placement of fixation points and dimensions of stimuli. Transverse test line $(A B)$ and vertical inducing line (CD) were $2^{\circ} 6^{\prime}$ and $10^{\circ} 35^{\prime}$ long, respectively. Fixation points: upper tip (B), lower tip (A), upper fixation point (U), lower fixation point (L). Lengths of UB and BL were $1^{\circ} 59^{\prime}$ and $3^{\circ} 3^{\prime}$, respectively, $\theta=45^{\circ}$. For other details (e.g., dots 1 to 10), see text.

but suffice it to note here that dots were aligned both at the upper tip (B) and the lower tip (A) of the transverse line, and that the inducing line, $C D$, was present in the experimental conditions but absent in the control conditions.

If results similar to those obtained by Prytulak (1973a) were to occur in our control conditions, then we could predict the relative magnitudes of the errors in the four fixation conditions shown in Figure 1, and in the fifth, free-inspection condition (F) which, as stated earlier, we expected not to differ from fixation Conditions $A$ and $B$. The usual parallelless Poggendorff effect is such that dots in Position 6 to 10 in Figure 1 would appear too high when aligned with $A B$. Fixation at $U$ would enhance this effect by making the whole axis (from 1 to 10 ) appear curved towards $U$. On the other hand, the usual Poggendorff effect makes the dots at Positions 1 to 5 appear too low. Hence, fixation of $U$ would detract from the illusion at the lower end of the line by making these dots appear too high. By similar reasoning, fixation of $L$ was expected to enhance illusions at the lower end of the line but detract from illusions at the upper end. From Prytulak's data, and the above discussion, no effect on the usual parallelless illusion was expected to occur as a consequence of fixation at $A$ or $B$ or with free inspection $(F)$. Hence, the predicted relative alignment error magnitudes at the upper end of the line were: $\mathrm{U}>\mathbf{A}=\mathbf{B}=\mathbf{F}>\mathrm{L}$; at the lower end, the predicted ordering was reversed: $\mathbf{L}>\mathbf{A}=\mathbf{B}=$ F $>$ U. 


\section{METHOD}

\section{Apparatus}

General. A PDP-11/20 computer was interfaced with an Alpha 16 minicomputer to produce visual displays on the flat face of a Tektronix 604 display monitor (P4 phosphor). The display was viewed in the dark, and during the experiment the glare from the screen was negligible so that its edges were only dimly visible after considerable dark adaptation. The observer was seated $540 \mathrm{~mm}$ from the screen with the head upright and eyes level with the display. This position was maintained by a dental-cement bite bar, one of which was prepared for each subject prior to testing while the subject partially dark-adapted in the dim experimental room. The experimenter controlled the display from an adjoining room, monitoring the subject's progress on another 604 display.

Visual display. The display can be described in relation to Figure 1. The test line (AB), inducing line (CD), and Dots 1, $3,5,6,8$, and 10 (Dots $2,4,7$, and 9 were not used in this experiment) all had a luminance of approximately $1.37 \mathrm{~cd} / \mathrm{m}^{2}$, estimated by measuring the luminance of a grid of lines. Since the background luminance was not measurable using an SEI photometer, the contrast of the stimulus elements, defined as $\left(\mathrm{L}_{\max }-\mathrm{L}_{\min }\right) /\left(\mathrm{L}_{\max }+\mathrm{L}_{\min }\right)$ exceeded 0.95 .

The test line, $\mathrm{AB}$, was always oriented $45^{\circ}$, and the inducing line, $C D$, when present, was vertical $\left(90^{\circ}\right)$. Hence $\theta$ was $45^{\circ}$. Dots 1,3 , and 3 , which were never presented simultaneously, were, respectively, $25 \mathrm{~mm}\left(2.65^{\circ}\right), 15 \mathrm{~mm}\left(1.59^{\circ}\right)$, and $5 \mathrm{~mm}$ $\left(0.53^{\circ}\right)$ from the lower tip (A); the distances of Dots 10,8 , and 6 from the upper tip (B) were the same.

The other stimulus dimensions were as follows: All line widths and dot diameters were $0.3 \mathrm{~mm}\left(0.03^{\circ}\right)$; the lengths of $C D$ and $A B$ were, respectively, $100 \mathrm{~mm}\left(10^{\circ} 35^{\prime}\right)$ and $19.8 \mathrm{~mm}\left(2^{\circ} 6^{\prime}\right)$. The fixation points ( $U$ and $L$ in Figure 1) were horizontal lines $12 \mathrm{~min}$ arc long. The entire screen was $13^{\circ} 55^{\prime}$ wide and $11^{\circ} 16^{\prime}$ high. The fixation points $U$ and $L$ were present only in the conditions in which they were used. However, in Condition $U$, for example, the $U$ fixation point was present both in the experimental condition (CD present) and in the control condition (CD absent).

Response box. The observer was provided with a box on which two microswitches were mounted, one above the other. If a dot appeared too high, above the apparent extension of $A B$, the observer pressed the upper switch; pressing the lower switch indicated that the dot appeared too low. Responding was selfpaced: the display was presented continuously until the observer responded, after which it was erased instantly for $1 \mathrm{sec}$ before the next trial.

\section{Procedure}

Each subject was tested under the experimental and control conditions with only one of the five fixation treatments: free inspection (F), upper (U), lower (L), upper tip (B), or lower tip (A), as in Figure 1. Test sessions lasted about $30 \mathrm{~min}$. Instructions were given using diagrams, and accuracy of judgments and care in maintaining fixation were stressed throughout the experiment, except in the free-inspection group to whom no instructions about fixation were given. The order in which a subject received the $C D$-absent control condition (C) and the $C D$-present experimental condition (E) was randomized.

On each trial, whether in Condition $\mathrm{E}$ or $\mathrm{C}$, one dot only appeared and the observer judged whether the dot appeared above or below the test line's extension. Thus, a point of subjective alignment (PSA) was measured at each of the six horizontal coordinates in Figure $1(1,3,5,6,8$, and 10). At each of these positions, a double, randomly interleaved staircase technique was used (Cornsweet, 1962; Wetherill \& Levitt, 1965). Initial step size was $1 \mathrm{~mm}$ (6 min arc), but after four reversals had occurred this was halved to $0.5 \mathrm{~mm}$ and the experiment continued until eight more reversals had occurred. [In previous experiments (e.g., Wenderoth et al., 1978), the standard deviation between subjects at Dot Positions 3 and 8 was about $0.7 \mathrm{~mm}$.] To avoid any implied vertical path for the dots, since the increments were on that axis, successive trials were selected randomly from Positions $1,3,5,6,8$, or 10 so that, although each response caused the dot to be displaced vertically up or down by one increment on the next trial in that position, the subject rarely experienced such increments because the six double staircases were themselves randomly interleaved. At each of the six positions, mean PSAs were calculated using the last eight reversals by averaging the eight values midway between the point of response reversal and the preceding trial. PSAs were calculated in units of dots on the screen and were later converted to errors in millimeters (10 dots per millimeter) or to angular degrees of displacement (see Results).

\section{Subjects}

Fifty volunteers from an introductory psychology course served as subjects in return for nominal course credit. All had normal or corrected vision. Each subject was randomly assigned to one of the five fixation conditions so that there were 10 subjects in each group.

\section{RESULTS}

The results are treated and presented in two ways, first in terms of errors in linear units (millimeters) and later in terms of angular displacements.

\section{Linear Measures}

Figures 2, 3, and 4 show the mean errors in millimeters, at each of the six dot positions in Figure 1, for the control conditions (Figure 2), experimental conditions (Figure 3), and the corrected $E$ minus $C$ data (Figure 4). The convention adopted in all cases is that positive errors reflect settings which err in the direction of the horizontal axis of

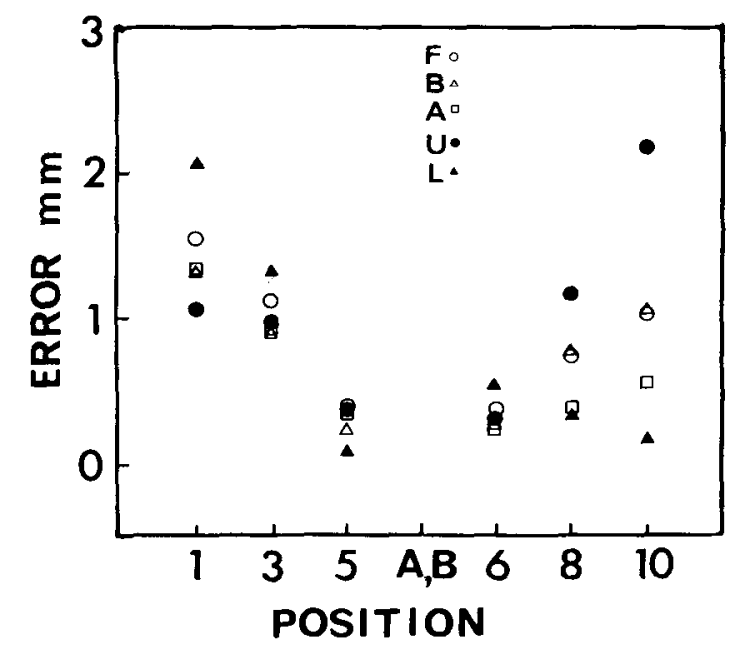

Figure 2. Mean vertical alignment errors, in millimeters, at each of the six dot positions, $1,3,5,6,8$, and 10 , in control conditions, C. Positive errors indicate errors in the direction of the horizontal axis of space. 
Table 1

Best-Fit Linear Regression Functions for Data in Figures 2, 3, and 4

\begin{tabular}{|c|c|c|c|c|c|c|c|c|c|c|}
\hline \multirow{2}{*}{$\begin{array}{c}\text { Fixation } \\
\text { Point }\end{array}$} & \multirow{2}{*}{$\begin{array}{l}\text { Line } \\
\text { End }\end{array}$} & \multicolumn{3}{|c|}{ Condition C } & \multicolumn{3}{|c|}{ Condition $\mathrm{E}$} & \multicolumn{3}{|c|}{ Condition E-C } \\
\hline & & $\mathrm{b}$ & $\mathrm{m}$ & $\mathbf{r}$ & $\mathrm{b}$ & $\mathrm{m}$ & $\mathbf{r}$ & b & $\mathrm{m}$ & $\mathbf{r}$ \\
\hline $\mathbf{F}$ & $\begin{array}{l}\text { A } \\
\text { B }\end{array}$ & $\begin{array}{l}+.36 \\
+.24\end{array}$ & $\begin{array}{l}+.049 X \\
+.032 X\end{array}$ & $\begin{array}{l}1.000 \\
1.000\end{array}$ & $\begin{array}{l}+.32 \\
+.57\end{array}$ & $\begin{array}{l}+.063 X \\
+.154 X\end{array}$ & $\begin{array}{l}.999 \\
.997\end{array}$ & $\begin{array}{r}-.12 \\
+.33\end{array}$ & $\begin{array}{l}+.018 X \\
+.123 X\end{array}$ & $\begin{array}{l}.986 \\
.995\end{array}$ \\
\hline B & $\begin{array}{l}\text { A } \\
\text { B }\end{array}$ & $\begin{array}{l}+.24 \\
+.12\end{array}$ & $\begin{array}{l}+.044 X \\
+.039 X\end{array}$ & $\begin{array}{r}1.000 \\
.992\end{array}$ & $\begin{array}{l}+.15 \\
+.68\end{array}$ & $\begin{array}{l}+.042 X \\
+.162 X\end{array}$ & $\begin{array}{l}.999 \\
.995\end{array}$ & $\begin{array}{l}+.10 \\
+.56\end{array}$ & $\begin{array}{l}-.008 X \\
+.123 X\end{array}$ & $\begin{array}{r}-.546 \\
.996\end{array}$ \\
\hline $\mathrm{U}$ & $\begin{array}{l}\mathbf{A} \\
\mathbf{B}\end{array}$ & $\begin{array}{l}+.25 \\
-.19\end{array}$ & $\begin{array}{l}+.037 X \\
+.094 X\end{array}$ & $\begin{array}{l}.909 \\
.999\end{array}$ & $\begin{array}{l}+.45 \\
+.40\end{array}$ & $\begin{array}{l}+.065 X \\
+.257 X\end{array}$ & $\begin{array}{l}.989 \\
.999\end{array}$ & $\begin{array}{r}-.17 \\
+.59\end{array}$ & $\begin{array}{l}+.046 X \\
+.163 X\end{array}$ & $\begin{array}{l}.922 \\
.996\end{array}$ \\
\hline$L$ & $\begin{array}{l}\mathbf{A} \\
\mathbf{B}\end{array}$ & $\begin{array}{l}-.32 \\
+.60\end{array}$ & $\begin{array}{r}+.099 X \\
-.017 X\end{array}$ & $\begin{array}{r}-.990 \\
.999\end{array}$ & $\begin{array}{l}-.02 \\
+.90\end{array}$ & $\begin{array}{l}+109 X \\
+.129 X\end{array}$ & $\begin{array}{l}.996 \\
.962\end{array}$ & $\begin{array}{l}+.29 \\
+.61\end{array}$ & $\begin{array}{l}+.010 X \\
+.137 X\end{array}$ & $\begin{array}{l}.924 \\
.978\end{array}$ \\
\hline A & $\begin{array}{l}\text { A } \\
\text { B }\end{array}$ & $\begin{array}{l}+.33 \\
+.23\end{array}$ & $\begin{array}{l}+.040 \mathrm{X} \\
+.013 \mathrm{X}\end{array}$ & $\begin{array}{r}1.000 \\
.982\end{array}$ & $\begin{array}{l}+.28 \\
+.45\end{array}$ & $\begin{array}{l}+.047 X \\
+.126 X\end{array}$ & $\begin{array}{r}.991 \\
1.000\end{array}$ & $\begin{array}{l}-.10 \\
+.30\end{array}$ & $\begin{array}{l}+.010 \mathrm{X} \\
+.109 \mathrm{X}\end{array}$ & $\begin{array}{r}.842 \\
1.000\end{array}$ \\
\hline
\end{tabular}

Note- $r=$ correlation between fitted lines and data points.

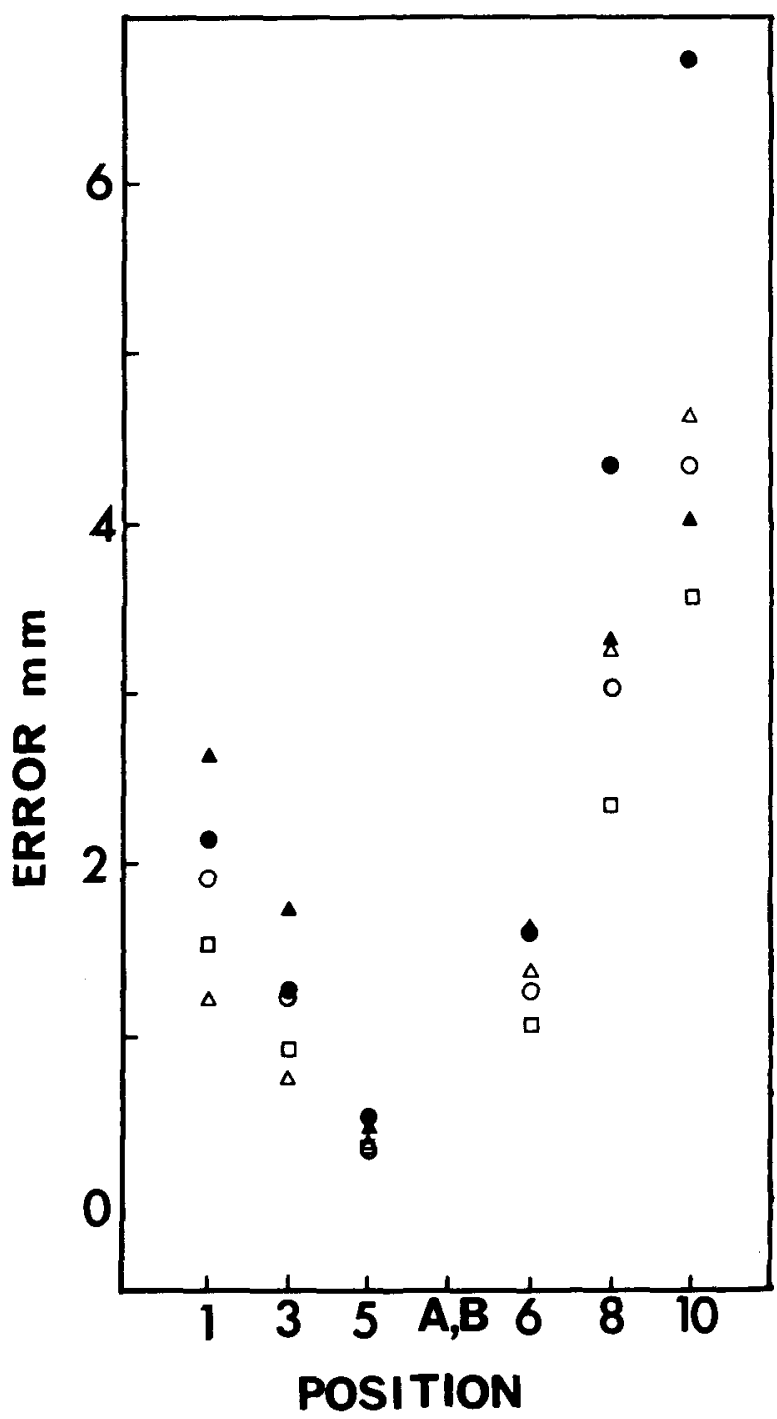

Figure 3. Mean vertical alignment errors in experimental conditions, E. Other details as for Figure 2. space. Thus, positive errors indicate settings which are too low in Positions 6, 8, and 10 but too high in Positions 1, 3, and 5. Clearly, most errors in Figures 2 to 4 are positive, in the direction of true horizontal.

Before discussing the detailed analyses of the data, some general descriptive points can be made about Figures 2 to 4 . First, in all cases and as predicted, there is very little difference between Conditions $F$ and B: fixating the upper tip (B) gives essentially the same result as free inspection, suggesting that subjects probably concentrate their fixations at or near $B$ under the free-inspection condition. This result does not therefore agree with that of Novak (1966), who found substantial decrement in the Poggendorff illusion due to fixation. However, as noted earlier, Novak's finding applies perhaps only to the complete classic Poggendorff figure with two inducing parallel and two transverse segments and to fixation beyond the point of abuttal.

Second, the relative magnitudes of the errors in the control condition (Figure 2) are almost entirely as predicted from Prytulak's results. For Dot Positions 6,8 , and 10 , the prediction was $U>F=B=$ $A>L$; the data show essentially this ordering. The reverse ordering was predicted for Positions 1, 3, and 5 , where the ordering is almost as predicted, namely $\mathrm{L}>\mathrm{F}=\mathrm{A}=\mathrm{B}>\mathrm{U}$. Certainly, the means for Conditions $U$ and $L$ seem strongly to confirm Prytulak's results.

Third, although unrelated directly to the aims of this experiment, the data replicate those of Wenderoth et al. (1978) in that they exhibit relatively large control errors in Condition $F$ at both ends of the test line and negligible errors at the lower tip (A) in the corrected $\mathrm{E}$ minus $\mathrm{C}$ data (Figure 4).

In order to test statistically for the effect of fixation conditions, the data in Figures 2 to 4 were collapsed further by averaging, for each subject, the three mean errors at each end of the test line. This 


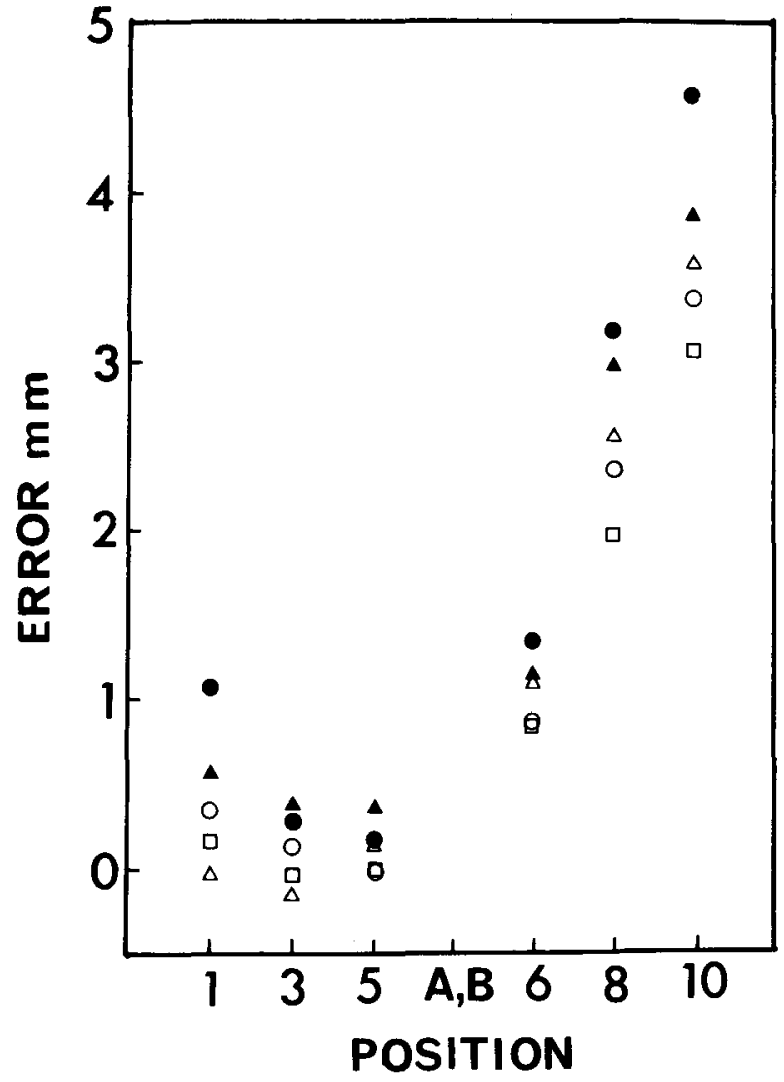

Figure 4. Mean vertical alignment errors for corrected (E-C) data. Other details as for Figure 2.

resulted in six scores for each observer: two mean errors, one at each end of the test line, for Conditions $C$ and $E$ and for the $(E-C)$ difference data. These errors, averaged over all subjects in each group, are shown in Figures 5 (Condition C), 6 (Condition E), and 7 (Condition $\mathrm{E}$ minus $\mathrm{C}$ ).

Six simple one-way analyses of variance were carried out on the data, one analysis for each of the six scores described above. ${ }^{2}$ In each analysis, the overall effect of fixation, with $4 \mathrm{df}$, was partitioned into four orthogonal contrasts. These were: Condition $F$ minus $B, U$ minus $L,(F+B)$ minus $(U+L)$, and $0.25(F+B+U+L)$ minus $A$. The last of these contrasts tested the null hypothesis that the effect of fixating line tip A did not differ from the overall mean effect of the other four conditions. This contrast was of minor interest since it merely happened to be the orthogonal test which remained after the three others had been specified.

In every case, the critical value of $F$ for significance was $(F .95)(1,45)=4.06$. The obtained $F$ ratios are set out in Table 2 , and those which exceeded the critical value are shown in italics. These results can be described in relation to Figures 5 , 6 , and 7.

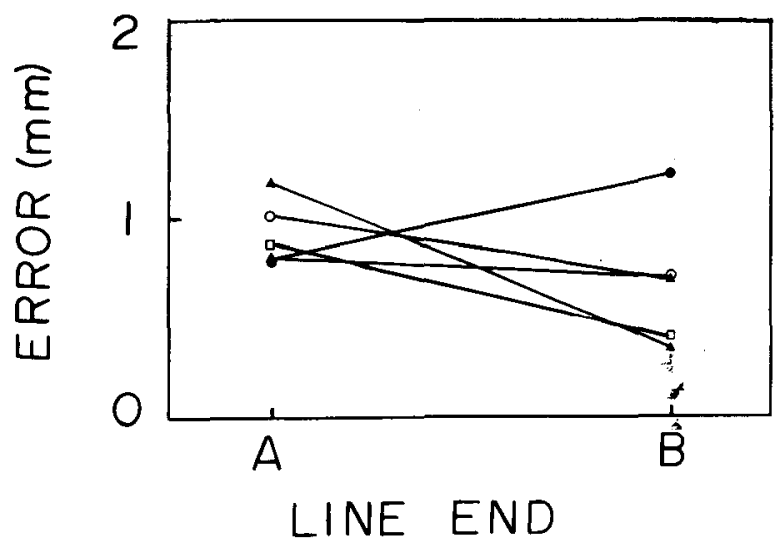

Figure 5. Mean errors (millimeters) averaged over three dot positions in Conditions $C$ at lower (A) and upper (B) ends of the test line. Other details as for Figure 2.

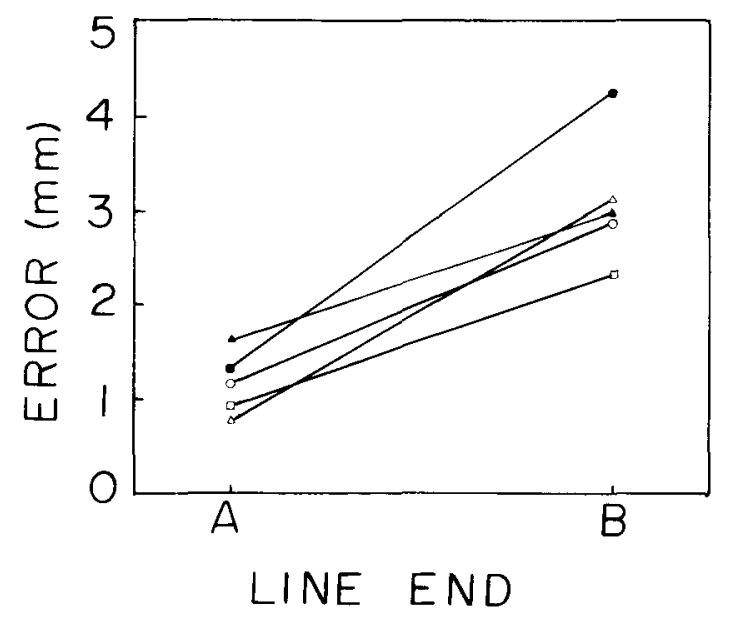

Figure 6. Mean errors (millimeters) in Condition E. Other details as for Figure 5.

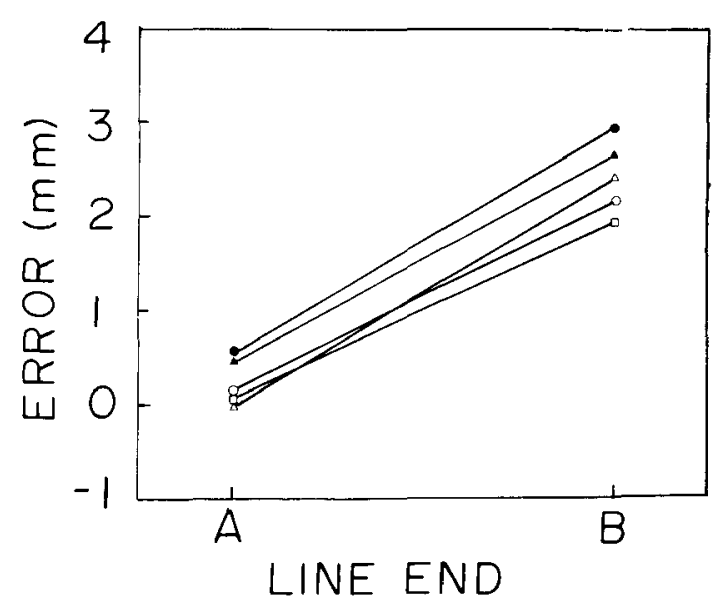

Figure 7. Mean (E-C) difference errors. Other details as for Figure 5. 
Table 2

Obtained F Values for Orthogonal Contrasts Between Fixation Conditions

\begin{tabular}{|c|c|c|c|c|c|}
\hline \multirow[b]{2}{*}{ Condition } & \multirow{2}{*}{$\begin{array}{c}\text { End of } \\
\text { Line }\end{array}$} & \multicolumn{4}{|c|}{ Contrast } \\
\hline & & {$[F-B]$} & {$[\mathbf{U}-\mathbf{L}]$} & {$[(\mathrm{F}+\mathrm{B})-(\mathrm{U}+\mathrm{L})]$} & {$[.25(\mathrm{~F}+\mathrm{B}+\mathrm{U}+\mathrm{L})-(\mathrm{A})]$} \\
\hline $\mathrm{C}$ & $\begin{array}{l}\text { A } \\
\text { B }\end{array}$ & $\begin{array}{l}.29 \\
.0003\end{array}$ & $\begin{array}{r}.95 \\
6.58\end{array}$ & $\begin{array}{l}.08 \\
.11\end{array}$ & $\begin{array}{r}.06 \\
1.60\end{array}$ \\
\hline $\mathbf{E}$ & $\begin{array}{l}\text { A } \\
\text { B }\end{array}$ & $\begin{array}{l}.87 \\
.15\end{array}$ & $\begin{array}{r}.53 \\
4.89\end{array}$ & $\begin{array}{l}2.94 \\
2.26\end{array}$ & $\begin{array}{r}.85 \\
4.44\end{array}$ \\
\hline E-C & $\begin{array}{l}\text { A } \\
\text { B }\end{array}$ & $\begin{array}{l}.37 \\
.24\end{array}$ & $\begin{array}{l}.07 \\
.39\end{array}$ & $\begin{array}{l}4.44 \\
2.45\end{array}$ & $\begin{array}{l}1.02 \\
2.77\end{array}$ \\
\hline
\end{tabular}

Note-Separate analyses of variance were carried out at the upper (B) and lower $(A)$ end of the test line for the control condition $(C)$, experimental condition $(E)$, and the $(E-C)$ difference scores. Critical value of $F_{95}(1,45)=4.06$ in all cases. Significant values are shown in italics.

The results of major interest are the $\mathrm{F}$ minus $\mathrm{B}$ and the $U$ minus $L$ contrasts in the $C, E$, and $\mathrm{E}$ - $\mathrm{C}$ data. Figure 5 for the $\mathrm{C}$ data shows that the $F$ and $B$ mean illusions were similar at both the lower end (A) of the line $(+1.01$ and $+0.80 \mathrm{~mm}$, respectively) and at the upper end (B) of the line $(+0.71$ and $+.70 \mathrm{~mm}$, respectively). Neither difference was significant (from Table $2, F=0.29$ and 0.0003 , respectively). These differences were also nonsignificant in the $E$ conditions, both at end $A$ $(+1.16$ and $+.77 \mathrm{~mm}$, respectively; $F=0.87)$ and at end $B(+2.89$ and $+3.11 \mathrm{~mm}$, respectively; $F=$ $0.15)$. Consequently, the same tests did not achieve significance in the $(E-C)$ data (end $A:+0.15$ and $+0.02 \mathrm{~mm} ; \mathrm{F}=0.37$; end $\mathrm{B}:+2.18$ and $+2.40 \mathrm{~mm}$; $F=0.24)$. Thus, fixation on the upper end, $B$, of the test line in no case resulted in any effect different from free, uninstructed inspection.

While the $U$ and $L$ means in the control condition did not differ significantly at the lower end of the line $(+0.80$ and $+1.17 \mathrm{~mm}$, respectively; $F=0.95$ ), there was a significant difference at the upper end $(+1.23$ and $+.30 \mathrm{~mm} ; F=6.58)$. The nonsignificant difference at the lower end $(0.37 \mathrm{~mm})$ was, however, in the expected direction such that in Figure 5 the $\mathrm{U}$ and $\mathrm{L}$ functions show a crossover effect.

This pattern of differences, including the crossover effect, is preserved in the $E$ data of Figure 6. Again, at the lower end the $\mathrm{U}-\mathrm{L}$ difference was nonsignificant $(+1.31$ and $+1.61 \mathrm{~mm} ; F=0.53)$, but it was significant at the upper end $(+4.25$ and $+2.97 \mathrm{~mm} ; \mathrm{F}=4.89$ ). As a result, the $U-L$ differences were not significant in the corrected $(E-C)$ scores, either at the lower end where the difference was small and opposite to both the $\mathrm{C}$ and $E$ differences $(+0.52$ and $+0.44 \mathrm{~mm} ; F=0.07)$ or at the upper end, where the difference was in the direction of the $E$ and $C$ data but was not now large enough for significance $(+2.95$ and $+2.66 \mathrm{~mm}$; $F=0.39$ ). Hence, these results are consistent with the hypothesis that $U$ and $L$ fixation affect line-dot alignments in the manner proposed by Prytulak (1973a), both when an inducing parallel is present and when it is absent; and hence, as Figure 7 shows, subtracting the $\mathrm{E}$ and $\mathrm{C}$ errors removes the crossover effect from the data.

The above results are those of major interest. Only two other contrasts are significant. In the (E - C) data of Figure 7, it can be seen that both the $U$ and $L$ functions lie entirely above the $F$ and $B$ functions. That is, in the corrected data, the means for both $\mathrm{U}$ and $\mathrm{L}$ exceeded those for $\mathrm{F}$ and $\mathrm{B}$.

At the lower end, the average of the $U$ and $L$ means $(+0.48 \mathrm{~mm})$ was significantly greater than that of the $F$ and $B$ means $(+0.07 \mathrm{~mm} ; \mathrm{F}=4.44)$, although this was not the case at the upper end $(+2.81$ and $+2.29 \mathrm{~mm}$, respectively; $F=2.45)$. However, as might have been expected, the withingroups standard errors were all sightly larger in the $U$ and $L$ than in the $F$ and $B$ conditions, so that one or two extreme scores in the more taxing $U$ and $L$ conditions boosted the overall means: the ranges of means in $F$ and $B$, at the upper end for example, were +0.93 to $+4.33 \mathrm{~mm}$ and +1.21 to $+4.16 \mathrm{~mm}$, respectively, while those in $U$ and $L$ were +1.48 to $+5.80 \mathrm{~mm}$ and +1.76 to $+4.38 \mathrm{~mm}$. Similarly, at the lower end, the respective ranges were -0.65 to $+1.39 \mathrm{~mm}$ in $\mathrm{F}$ and -0.48 to $+0.54 \mathrm{~mm}$ in $\mathrm{B}$, while the corresponding ranges in $\mathrm{U}$ and $\mathrm{L}$ were -0.36 to $+1.93 \mathrm{~mm}$ and -0.39 to $+1.14 \mathrm{~mm}$.

The remaining significant difference occurred in the fourth contrast where the mean for the A condition in the uncorrected $E$ scores at the upper end of the line $(+2.34 \mathrm{~mm})$ differed from the mean of all other groups $(+3.31 \mathrm{~mm})$, a difference attributable mainly to the large effect in the $U$ condition (Figure 6).

\section{Angular Measures}

In previous experiments using similar displays and tasks, we had found that linear functions, fitted to mean errors in millimeters at each dot position (e.g., as in Table 1), extrapolated close to the nearest 
tip of the oblique line (e.g., Wenderoth et al., 1978). This was also true in the present experiment since, as Table 1 shows, all of the fitted functions had linear intercepts smaller than $1 \mathrm{~mm}$, whereas the test line itself was almost $20 \mathrm{~mm}$ long.

Initially, and on the assumption that these intercepts were sufficiently close to zero, the alignment error for each subject at each dot position was converted to an angular error, using the nearest line tip as origin, from the formula

$$
\alpha=[90-\theta]-\tan ^{-1}[\tan (90-\theta)-d / w],
$$

where $\theta$, in this case, equals $45^{\circ}$, w is the horizontal distance between the oblique line's tip and the dot (3.54, 10.61, and $17.68 \mathrm{~mm}$, respectively, for the near, middle, and far dots at each line end) and $d$ is the obtained alignment error in millimeters.

When this was done and the data were averaged to produce angular data corresponding to the linear data in Figures 2 to 4, the results were those shown in Figures 8 (Condition C), 9 (Condition E) and 10 (E minus $\mathrm{C}$ ).

As was the case with the millimeter data (Table 1), the fitted linear functions described the data well. Many of the correlations between the data and the linear functions were high and the goodness of fit can be seen in Figures 8 to 10 , in which the best-fit lines appear. However, the most noticeable aspect of Figures 8 to 10 is the clear negative slope in some cases, particularly at the upper end of the test line (Positions 6 to 10$)$ in the $E$ and the $(E-C)$ data.

If errors increased linearly with line-to-dot separation and extrapolated to the tip of the test line, then errors in angular terms would be identical at each dot position and all functions in Figures 8 to 10 would be horizontal. Figure 11a illustrates how the alignment error remains constant as the linear

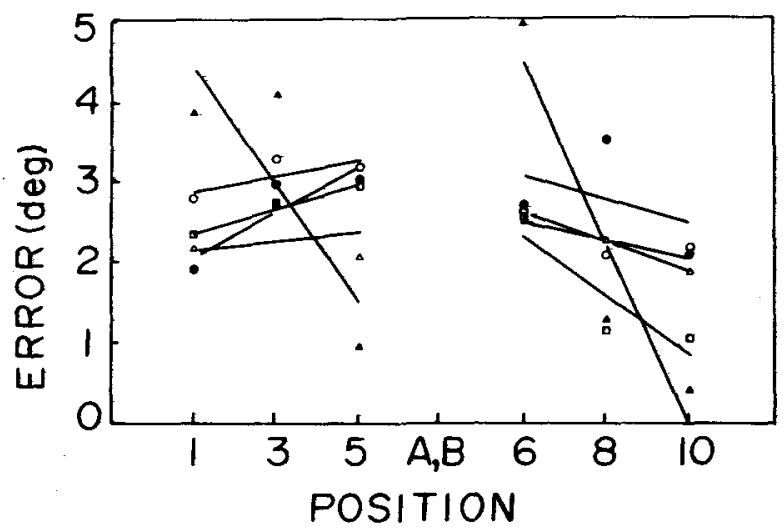

Figure 8. Mean converted angular errors at each dot position in Condition $C$ with best-fit linear functions. Symbols as for Figure 2. Details of angular conversion given in text.

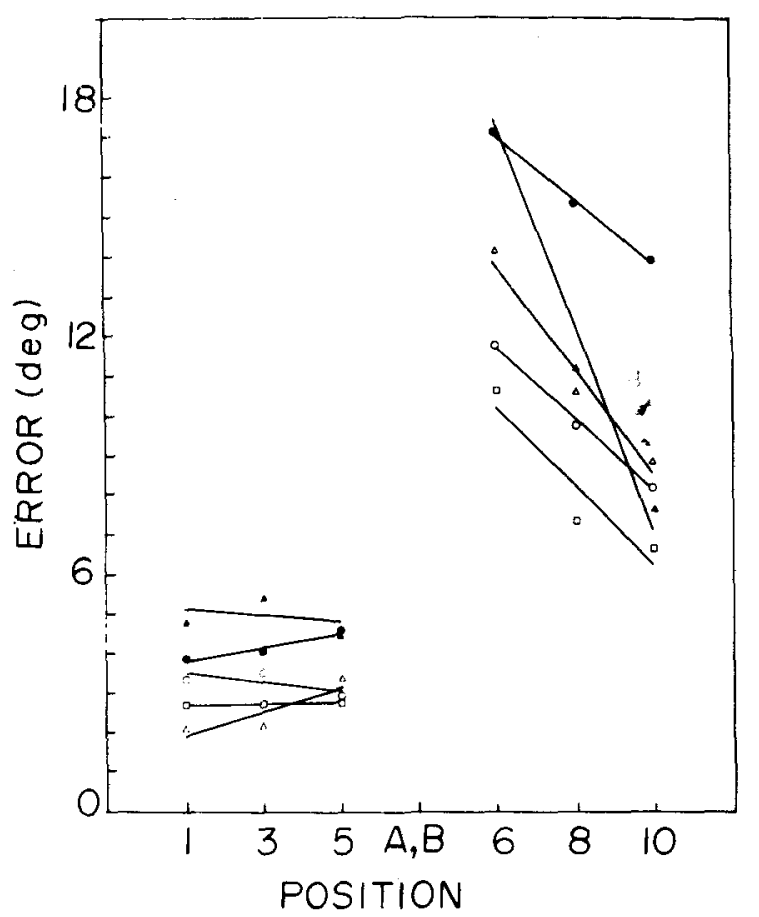

Figure 9. Mean converted angular errors at each dot position in Condition $\mathbf{E}$ with best-fit linear fanctions. Other detalls $\mathbf{a}$ for Figure 8.

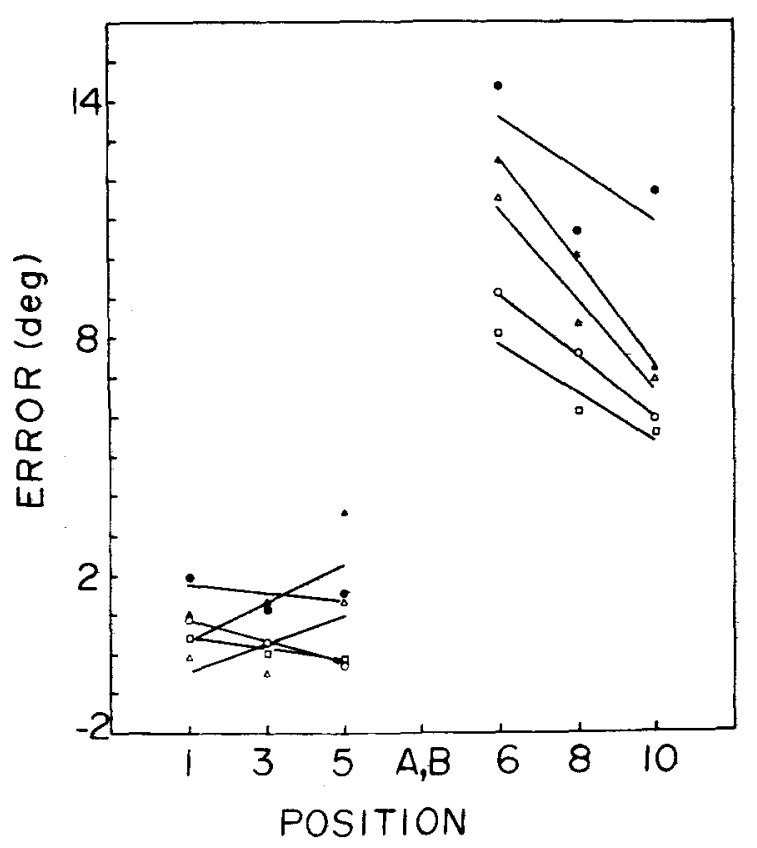

Figure 10. Mean converted angular errors in Condition $\mathbf{E}$ minus those in Condition $\boldsymbol{C}$ with best-fit linear functions. Other details as for Figure 8. 
(a)

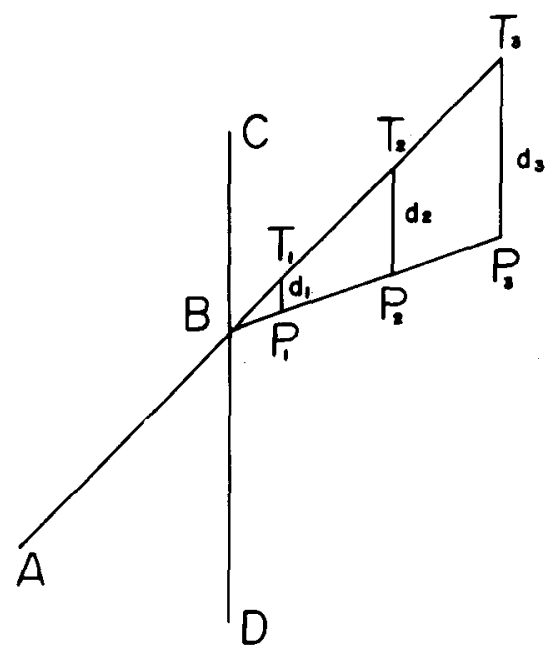

(b)

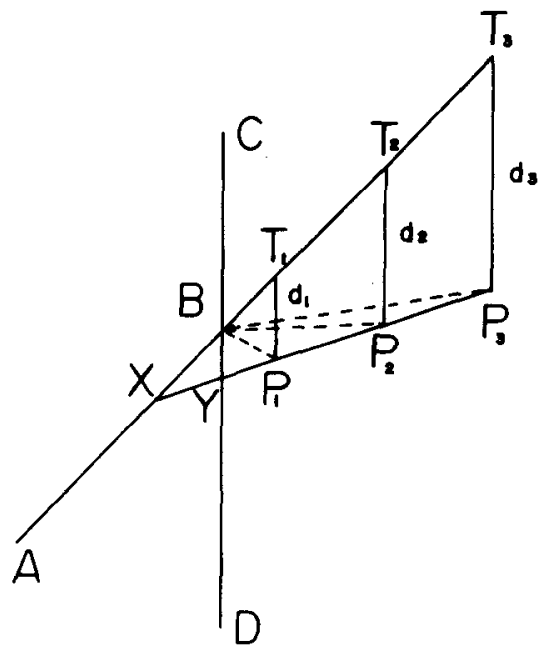

Figure 11. Relationship between linear alignment errors $\left(d_{1}\right.$ to $d_{3}$ ) and angalar errors when mean points of alignment (a) extrapolate to point $B$ and (b) extrapolate to point $X$. See text for details.

deviation $\left(d_{1}\right.$ to $\left.d_{3}\right)$ between the true path of alignment $\left(T_{1}\right.$ to $\left.T_{3}\right)$ and the perceived path $\left(P_{1}\right.$ to $\left.P_{3}\right)$ increases. However, Figure 11a does not adequately describe the data reported above, and the explanation of the negatively sloping functions in Figures 8 to 10 is shown in Figure $11 \mathrm{~b}$.

Here the perceived path of alignment, although linear, does not extrapolate to the line endpoint $B$. Rather, it extrapolates to a point (X) inside the line and there is a small positive intercept (BY), which is exaggerated in the figure. In this case, alignment errors still increase linearly with line-to-dot separation but the angular deviations of points $\mathrm{P}_{1}$ to $\mathrm{P}_{3}$ from the true abuttal point, $\mathrm{B}$, decrease with distance from $\mathrm{B}$ so that angle $T_{1} B P_{1}>T_{2} B P_{2}>T_{3} B P_{3}$. These inequalities are quite large in the example shown, even though Figure $11 \mathrm{~b}$ is drawn to scale and the linear intercept (BY) is only $+3.08 \mathrm{~mm}^{3}$

The fact that Figure $11 \mathrm{~b}$ does better represent the data of this experiment than Figure 1la can be seen from Table 1. In the $E$ and $(E-C)$ data, for which negatively sloping functions are most pronounced in Positions 6 to 10 , the intercepts are all positive and relatively large, ranging from +0.30 to $+0.90 \mathrm{~mm}$. In general, at the lower end of the line (Positions 1 to 5) the 15 linear intercepts in Table 1 are roughly rectangularly distributed, with a mean of $+0.14 \mathrm{~mm}$. At the upper end of the line, however, the distribution of linear intercepts is negatively skewed with a mean of $+0.40 \mathrm{~mm}$ but with almost half of the intercepts exceeding $+0.50 \mathrm{~mm}$. Thus it can be understood why the linear functions in Figures 8 to 10 are relatively flat for Positions 1 to 5, where the linear intercepts are small and are distributed around zero, but are negatively sloping in many cases for Positions 6 to 10, where the intercepts are larger and more frequently positive.

At first glance, it is tempting to conclude, from Figures 9 and 10, that significantly nonzero intercepts occurred mainly at the abutting end of the test line, since the negatively sloping functions occur generally in Positions 6 to 10. This would suggest that positive intercepts somehow are attributable to the effect of the inducing line, a point to be taken up in the Discussion. However, the control data (Figure 8) also exhibit nonhorizontal functions. In particular, and as Table 1 shows, upper fixation resulted in a positive intercept in Positions 1 to 5 $(+0.45 \mathrm{~mm})$ and a negative intercept in Positions 6 to $10(-0.19 \mathrm{~mm})$, whereas the reverse was true of the lower fixation $(-0.02$ and $+0.60 \mathrm{~mm}$, respectively). On the other hand, the control data intercepts for the other three fixation conditions were all slightly positive and similar in magnitude at both ends of the line. In brief, while there is some evidence that large positive intercepts are associated with the presence of the inducing line, there is also evidence that changing the point of fixation also affects the intercept. Fixation at $L$ seems to shift the whole perceived path downwards towards $L$, resulting in more positive intercepts in Positions 6 to 10 and more negative intercepts at Positions 1 to 5. Conversely, fixation at $U$ shifts the whole error function upwards, making intercepts more negative in Positions 6 to 10 , more positive in Positions 1 to 5 . Associated with these changes in intercept there are also changes in slope: In the $E$ data of Table 1, for example, lower fixation is associated not only with a more positive intercept than upper fixation in Positions 6 to 10, but also with a smaller slope (.013 vs. .026), whereas the reverse is true in Positions 1 to 5 (.011 vs. .007). These slope differences are evident in Figures 2 to 4. 


\section{DISCUSSION}

Several conclusions can be drawn from this experiment, but questions are also raised by the data.

The first conclusion is that, under the stimulus conditions used here, virtually identical alignment errors occur under conditions of free, uninstructed inspection and in the condition in which the observer is required to fixate the upper end of the test line (the intersect end in treatment $E$ ). The data thus do not support Novak's finding that fixation per se reduces Poggendorff effects, although various differences between our stimulus conditions and those of Novak have been mentioned earlier and these might account for the difference. If nothing else the present results strongly suggest that the issue requires further investigation.

The second conclusion that can be drawn from this study is that fixation $2^{\circ}$ or so above the upper tip of the test line or $3^{\circ}$ or so below it induces effects similar to those reported by Prytulak (1973a): dots truly aligned with the test line appear displaced towards the fixation point. This effect occurs not only in the case of simple line-dot alignments (our control conditions) but also when an inducing parallel is present (experimental conditions). The consequence is that both the parallelless Poggendorff effect and the effect with the inducing line are either enhanced or reduced by upper or lower fixation, depending upon whether the fixation effect is in the same direction as the Poggendorff illusion or is directionally opposite. When the effect of the inducing line per se is estimated by taking difference scores between the experimental and control data, such effects of peripheral fixation are no longer significant.

Although these results were predicted by us, they are not in accord with the recent report of Greist and Grier (1977) to the effect that $3.12^{\circ}$ peripheral vertical fixation of the full Poggendorff figure eradicates the illusion entirely. However, Greist and Grier used a small, $1.25^{\circ}$ stimulus so that the entire figure fell on the retinal periphery. Our figure was much larger and similar in magnitude to Novak's (1966). At any rate, it is difficult to assess the Greist and Grier result since they did not include a control condition similar to ours. It is at least conceiveable that, with their stimuli, a reverse Poggendorff effect might occur in the absence of any inducing parallels. If so, the effect of the inducing lines could be preserved in $E$ minus $C$ data, as was found to be the case here. It is at least puzzling to note that Prytulak's effect, which we have clearly confirmed in this experiment, was not evident in the Greist and Grier experiment.

A final point of discussion concerns the explanation of the variability in slopes and intercepts in
Table 1 and in Figures 2 to 4 . First, it cannot be concluded with any confidence that linear functions do best describe the data. Although the correlations between the functions and the data are high, with only three data points a correlation of 0.997 is required for significance at the .05 level. It is conceivable that additional experiments using more lineto-dot separations will show that the effects of fixation are better described by variations in curvilinear functions (Prytulak, 1973a) than by changes in linear slopes and intercepts. However, leaving this issue aside, there remains to be explained the fact that intercepts were generally positive in Conditions $F$ and $B$, particularly in Positions 6 to 10 in the $E$ and $(E-C)$ data.

We have postulated elsewhere that a long test line is processed in subunits and units closer to the inducing line are more strongly affected so that the test line appears bowed (Wenderoth et al., 1978). It is also known that the arms of acute angles appear shorter than the arms of obtuse angles (e.g., Judd, 1899). One hypothesis, then, is that the test line does bow or "club" (Schilder \& Wechsler, 1936) at the point of abuttal such that its perceived tip is, in Figure 1, below the true point of abuttal. If so, this would account for the preponderance of large positive linear intercepts in Positions 6 to 10 in the $E$ and $(E-C)$ data but, at the same time, would render inappropriate any conversion of linear to angular errors which uses the true point of abuttal as the origin of those errors.

\section{REFERENCES}

CoRnsweet, T. N. The staircase method in psychophysics. American Journal of Psychology, 1962, 75, 485-491.

CURthoys, I., Wenderoth, P., \& Harris, J. The effects of the motion path and the length of the variable segment in the Poggendorff illusion without parallels. Perception \& Psychophysics, 1975, 17, 358-362.

DAY, R. H. The oblique line illusion: The Poggendorff effect without parallels. Quarterly Joumal of Experimental Psychology, 1973, 25, 535-541.

DAY, R. H., \& Dickinson, R. G. The components of the Poggendorff illusion. British Journal of Psychology, 1976, 67, 537-552.

Greist, S. M., \& Grier, J. B. The effect of retinal location on the magnitude of the Poggendorff illusion. Perception \& Psychophysics, 1977, 21, 249-252.

Helmioltz, H. L. F. voN. Handbuch der physiologischen Optik. Hamburg and Leipzig: Voss, 1920. (Translated by J. P. Southall (Ed.), Helmholtz's treatise on physiological optics) (Vol. III). Rochester, N.Y: The Optical Society of America, 1925.

Judd, C. H. A study of geometrical illusions. Psychological Review, 1899, 6, 241-261.

Novax, S. Effects of free inspection and fixation on the magnitude of the Poggendorff illusion. Perceptual and Motor Skills, 1966, 23, 663-670.

Parlee, M. B. Differences in apparent straightness of dot and line stimuli. Vision Research, 1972, 4, 735-742. 
Prytulax, L. S. The effect of fixation point on the appearance of rectilinearity. Perception \& Psychophysics, 1973, 14, 387-393. (a)

Prytulax, L. S. Interaction of fixation point and stimulus orientation on the appearance of rectilinearity. Perception \& Psychophysics, 1973, 14, 493-496. (b)

SChilder, P., \& Wechsler, D. The illusion of the oblique intercept. Journal of Experimental Psychology, 1936, 19, 747-757.

Tong, L., \& Weintraus, D. J. Contour displacements and tracking errors: Probing 'twixt Poggendorff parallels. Perception \& Psychophysics, 1974, 15, 258-268.

Wenderoth, P., Beh, H., \& White, D. Perceptual distortion of an oblique line in the presence of an abutting vertical line. Vision Research, 1978, in press.

Wetrerill, G. B., \& LeVITt, H. Sequential estimation of points on a psychometric function. British Journal of Mathematical \& Statistical Psychology, 1965, 18, 1-10.

Wundt, W. Grundzüge der physiologischen Psychologie. Leipzig: Engelmann, 1886.

\section{NOTES}

1. From the literature, it is not clear under what conditions peripheral stimuli appear concave towards the fixations point (barrel distortion) or convex (pincushion distortion). Prytulak (1973a) outlined a model in which barrel distortion occurs within only $3.5^{\circ}$ of fixation but did not test the effects which occurred at large eccentricities yet still in the region of the stimulus line. Thus the change from barrel to pincushion distortion in his data may have been contingent on fixation near the response dot rather than upon the degree of eccentricity (see Prytulak, 1973b). Parlee's finding of barrel distortion with fixation eccentrically $10^{\circ}$ in the region of lines or dots is consistent with this interpretation.

2. It was recognized that these three sets of scores, namely C, E, and (E-C) are not independent. Even so, it was considered useful to test whether, for example, a $U$ vs. $L$ effect did occur in both the $C$ and $E$ data but not in the corrected (E-C) scores, rather than merely to test for the absence of such an effect in the corrected data.

3. Tong and Weintraub (1974), p. 267) made the point that angular deviations obtained from millimeter conversions will vary as a function of separation of Poggendorff parallels when the deviations increase linearly with separation but the intercept is nonzero.

(Received for publication October 4, 1977; revision accepted May 31, 1978.) 